\title{
Dairy producer attitudes to pain in cattle in relation to disbudding calves
}

\author{
I. Wikman, ${ }^{*} \dagger^{1}$ A.-H. Hokkanen, ${ }^{*} \dagger$ M. Pastell, ${ }^{*} \ddagger$ T. Kauppinen, ${ }^{*} \dagger$ A. Valros, ${ }^{*} \dagger$ and L. Hänninen ${ }^{*} \dagger$ \\ ${ }^{*}$ Research Centre for Animal Welfare, Faculty of Veterinary Medicine, PO Box 57, Fl-00014 University of Helsinki, Finland \\ †Department of Production Animal Medicine, Faculty of Veterinary Medicine, PO Box 57, FI-00014 University of Helsinki, Finland \\ ‡Department of Agricultural Sciences, PO Box 28, FI-00014 University of Helsinki, Finland
}

\begin{abstract}
Pain is an important indicator of poor welfare of livestock. Despite this, pain has largely gone unrecognized in farm animals due to attitudes of producers and veterinarians, although they play a key role in monitoring and managing the perception of animal pain. Producer attitudes toward animal welfare influence livestock management and production. The aim was to quantify dairy producer attitudes to the painfulness of various cattle diseases and disbudding, a painful routine procedure performed on farm to ensure safer handling of cattle. A questionnaire on disbudding-related opinions and practices was sent to 1,000 Finnish dairy producers (response rate: 45\%). Attitudes toward disbudding were gauged using a 5-point Likert scale and attitudes to cattle pain scored on an 11-point numerical rating scale. Principal components analysis was used to assess the loadings, which were further tested for differences between producer gender and housing systems with Mann-Whitney U-tests, and between herd milk yield, herd size, and age and work experience of producers with a Kruskal-Wallis test. Four main factors were identified: factor I ("taking disbudding pain seriously"), factor II ("sensitivity to pain caused by cattle diseases"), factor III ("ready to medicate calves myself"), and factor IV ("pro horns"). Female producers took disbudding pain more seriously, were more sensitive to pain caused to cattle by diseases, and were more ready to medicate disbudded calves than male producers. Producers with tie-stalls favored horns over producers with freestalls. Male producers with tie-stalls were sensitive to cattle pain and preferred horns over male producers with freestalls. Female producers with freestalls were more ready to medicate calves, but did not prefer horns more than female producers with tie-stalls. Taking disbudding seriously correlated with sensitivity to pain caused by cattle diseases. Producers with low-milkyielding herds were less willing to medicate calves and more willing to keep cattle with horns than producers
\end{abstract}

Received September 5, 2012.

Accepted August 13, 2013.

${ }^{1}$ Corresponding author: ingela.wikman@helsinki.fi with higher-yielding herds. Older producers were more sensitive to cattle pain than middle-aged and younger producers. No effect was established for taking disbudding pain seriously: the pro-horn factor was associated with work experience, age, and herd size. Women rated pain higher and were more positive toward pain medication for animals than men. Maintaining horns are more important for producers with tie-stalls than for those with freestalls.

Key words: dairy cattle welfare, disbudding, pain, producer attitude

\section{INTRODUCTION}

Pain has a substantial effect on animal welfare: the greater the pain the poorer the welfare (Broom, 1991). Pain has often gone unrecognized in farm animals due to attitudes of producers and veterinarians, but also for economic reasons (Huxley and Whay, 2006; Weary et al., 2006; Viñuela-Fernández et al., 2007). In addition, part of the evolutionary strategy of prey species has relied on their not showing any signs of pain, sickness, or weakness in the face of predators (Huxley and Whay, 2006; Viñuela-Fernández et al., 2007). It is, therefore, not easy for producers to see the signs of pain and hence poor welfare of dairy cattle can result.

Producers play a key role when it comes to recognizing pain, taking care of the animals, and alleviating pain. The producer is the main caregiver and influences animal welfare, health, and production (Coleman et al., 2003; Hemsworth, 2003). According the theory of planned behavior, human behavior is guided by an individual's behavioral intention and behaviors are shaped by his or her attitude toward the behavior, subjective norms, and perceived behavioral control (Ajzen, 2002). A positive attitude toward cattle leads to positive human-cattle interactions (Raussi, 2003) and better animal handling (Grandin, 2000). Several studies have been done on producer attitudes to animal welfare (Hemsworth et al., 2002; Waiblinger et al., 2002; Coleman et al., 2003) and corresponding production figures (Hanna et al., 2009; Kauppinen et al., 2012). However, no studies have been done on how attitudes to cattle pain are reflected in dairy producer behavior. 
Routine painful procedures, such as disbudding cattle, are performed on farm. According to legislation of most European countries, disbudding can be performed on calves less than $4 \mathrm{wk}$ old without anesthesia or pain medication by a skilled person (ALCASDE, 2009), although use of sedation, local anesthetics and nonsteroidal antiinflammatory drugs is recommended for calves to be disbudded (AVA, 2004; New Zealand Government, 2005; AVMA, 2012). However, in countries such as Finland, in which the use of animal drugs is very restricted and tightly controlled (Act on the Medical Treatment of Animals 617/1997; Finlex, 1997), it is not possible for producers themselves to use local anesthetics and sedatives to alleviate calf pain during disbudding. Thus, application of medical pain relief for disbudded calves requires the producer to use a veterinarian.

Disbudding practices and pain medication were studied previously (Hewson et al., 2007; Misch et al., 2007; Fulwider et al., 2008) as well as farmer opinions regarding the use of pain medication (Gottardo et al., 2011). The novelty of our study lies in the aim to investigate producer attitudes toward calf pain during disbudding as an indicator of overall attitude toward treating cattle pain.

Gender may play a role in assessing pain in animals. Several studies showed that female veterinarians assess pain in animals to be stronger than male veterinarians do (Capner et al., 1999; Huxley and Whay, 2006; Fajt et al., 2011). Also female veterinary students show more empathy than male colleagues toward animals (Paul and Podberscek, 2000; Kielland et al., 2009; Hazel et al., 2011). Similar studies have not been conducted among producers.

Age and work experience may have contrasting effects on pain assessment. Younger veterinarians rate pain higher and treat pain more than older veterinarians do (Raekallio et al., 2003), and medical students have been shown to rate more chronic conditions as more painful than older colleagues (Niemi-Murola et al., 2007). Moreover, the empathy of medical students was reported to decline during their education (Hojat et al., 2004; Neumann et al., 2011). On the other hand, work experience has been related to higher pain rating by cattle veterinarians (Huxley and Whay, 2006) and veterinary nurses (Coleman and Slingsby, 2007). No studies exist on the effect of producers' experience and age on their attitudes toward cattle pain.

Cattle housing systems have moved from conventional tie-stalls to modern freestalls in Finland. Currently, approximately equal numbers of dairy cows are housed using each of the 2 systems (Tike, 2011). However, no studies have been done on the possible differences in animal welfare attitudes associated with tie-stall barns and freestalls, or young and old producers. Such issues are of growing importance due to the major changes producers have faced during the last 2 decades.

Our aim was to study dairy producer attitudes to the painfulness of different cattle diseases and practices, using disbudding as a model painful procedure, and to establish background factors associated with such attitudes.

\section{MATERIALS AND METHODS}

\section{Questionnaire}

In spring 2010, we sent a 4-page, postage-paid questionnaire to 1,000 Finnish dairy producers. The research was approved by the Finnish Agency for Rural Affairs. Producers were selected randomly from a geographically balanced list of all 11,224 dairy producers in Finland (Tike, 2011). The questionnaire was available in the 2 official languages of Finland, Finnish and Swedish, so that all dairy producers were able to respond in their mother tongue. The questionnaire was tested on 10 dairy producers, before being distributed, to ensure it was appropriate and valid. The dairy producers' names did not appear in the questionnaires and we analyzed all data without identifying the respondents or their farms.

The questionnaire consisted of 5 sections. The first section (background information) included 14 questions on basic issues about the respondent and their farm, including producer gender, barn type, length of time employed as a dairy producer, herd size, and milk yield. The second section (disbudding of calves) included 6 questions about on-farm disbudding and the association of horns with dangerous situations, and on the occurrence of polled, hornless, and horned cattle. The third section (disbudding practices) was intended only for producers performing disbudding and the 11 questions were related to how disbudding was performed on the farm (e.g., who disbuds on the farm, whether pain medication and analgesia are used, at what age disbudding occurs and if the producer is aware of training in disbudding). Some of the results from sections 1 to 3 are reported elsewhere (Hokkanen et al., 2011).

Section 4 (attitudes to disbudding) was intended for all producers, regardless of whether disbudding was done on the farm or not. In this section, we asked the respondents to rate their agreement with 25 disbudding-related and animal welfare-related statements on a 5-point Likert scale (Raekallio et al., 2003). The scores ranged from 1 to 5 , in which 1 corresponded to complete disagreement and 5 to complete agreement. In section 5 (pain in dairy cattle), we asked for opinions about cattle diseases and practices that caused pain 
to cattle. The evaluation was made using an 11-point numerical rating scale and included 14 statements (Huxley and Whay 2006; Hudson et al., 2008; Kielland et al., 2010). The scores ranged from 0 to 10 , where 0 represented no pain and 10 the highest degree of pain. The questionnaire included 70 questions. This was part of a larger study and in the current paper, we only describe results from sections 4 to 5 .

\section{Statistical Analysis}

In total, $451(45 \%)$ of the 1,000 farmers responded to the questionnaire, of which 12 respondents did not reply to the statements in parts 4 and 5 and were, therefore, excluded from the analysis. Answers from a total of 439 respondents were analyzed ultimately.

Factor analysis with principal components analysis (PCA) was used to establish summary variables in the data to be used in further analyses. The 25 different statements concerning disbudding (section 4) and 14 statements concerning cattle pain (section 5) were used in promax rotation in the factor analysis with PCA. Eigenvalues over 1 were extracted and variables with communalities below 0.3 were omitted (Zhan and Shen 1994; Knapp and Brown 1995; Vaartio et al., 2009). The missing values were replaced with means.

The loadings of the factors, or the correlation coefficients of rows and columns, in the PCA factor analysis gave a total of 11 different components for the 24 different statements. Negative loadings were converted into positive ones. If the Cronbach's $\alpha$ value was under 0.7, the component was omitted (Knapp and Brown 1995).

Before analyses, the herd size was categorized as 1 to 20,21 to 40,41 to 60 , and $>61$. The classification was done to correspond with the relatively small size of Finnish dairy farms. The difference in age between the producer genders was first tested with Mann-Whitney U-test and then age of the respondent was categorized as $\geq 55 \mathrm{yr}, 40$ to $54 \mathrm{yr}$, and $\leq 39 \mathrm{yr}$. The differences in and factor loadings between gender and barn types (tie-stall or freestall) were tested with a Mann-Whitney U-test. The difference in factor loadings among farmers with differing milk yield $(\leq 8,000 \mathrm{~L} / \mathrm{yr}, 8,001-10,000$ $\mathrm{L} / \mathrm{yr}$, or $>10,000 \mathrm{~L} / \mathrm{yr}$ ) and herd size and farmers of different age and with different work experience $(0-5$ yr, 6-10 yr, 11-20 yr, or >20 yr were tested first with a Kruskal-Wallis test and, if statistically significant, pairwise comparisons were tested with a Mann-Whitney U-test using Bonferroni corrections. The correlations between the factor loadings were analyzed with Spearman rank tests and only correlations with coefficients over 0.25 are reported here. The software PASW 18.0.1 (SPSS Inc., Chicago, IL) was used for the statistical analyses.

\section{RESULTS}

We secured 4 main factors with 3 to 9 loadings and a Cronbach's $\alpha$ value of 0.79 to 0.83 (Table 1). Factor I (termed "taking disbudding pain seriously") had 9 loadings: 6 positive and 3 negative. The loadings included 8 disbudding statements. Factor II (termed "sensitivity to pain caused by cattle diseases") had 7 positive loadings for farmer attitudes toward cow and calf pain. Factor III (termed "ready to medicate calves myself") had 3 positive loadings, all on the disbudding statements about producer willingness to medicate calves were it an option. Factor IV had 5 loadings: 4 positive and one negative, all on the disbudding statements (termed "pro horns"). The 4 factors explained $36.9 \%$ of the variance in the data.

\section{The Relationship Between Respondent Gender and Age}

A difference existed between the gender and age in the age medians (Mann-Whitney, $P=0.013$ ). Results are presented as numbers and medians (interquartile ranges in parentheses): men $=255$ and 1,961 (13); women $=175$ and 1,963 (12). No difference existed in the age medians for male and female respondents concerning the different age categories (Mann-Whitney, $P$ $>0.05$ ). Results are presented as numbers and medians (interquartile ranges in parentheses): male respondents born between 1940 and 1955: $\mathrm{n}=80,1951$ (6); male respondents born between 1956 and 1970: $\mathrm{n}=128,1962$ (6); male respondents born between 1971 and 1989: $\mathrm{n}$ $=47,1975$ (7); female respondents born between 1940 and 1955: $\mathrm{n}=29,1952$ (5.50); female respondents born between 1956 and 1970: $\mathrm{n}=110,1962$ (7.0); and female respondents born between 1971 and 1989: $\mathrm{n}=36$, $1976.5(5)$.

\section{The Relationship Between Gender and Barn Type and Factor Loadings}

Loadings for factor I ("taking disbudding pain seriously"), factor II ("sensitivity to pain caused by cattle diseases"), and factor III ("ready to medicate calves myself") differed significantly between male and female respondents: females had higher positive median loadings than males (Table 2). Loadings for the different barn types differed only for factor IV ("pro horns"): producers with tie-stalls had a lower median negative loading than producers with freestalls (Table 2).

However, we established associations between barn types and gender (Table 3). Male producers with tiestalls had a higher positive median loading than those with freestalls for factor I ("taking disbudding pain 
Median attitude

Factor I: taking

Factor II:

disbudding pain

sensitivity to

Factor III: ready

seriously

cattle disease

to medicate

Factor IV:

Statement about disbudding (Likert)

Disbudding without medication causes the calf pain

The calf requires no pain medication for disbudding

The calf may feel pain for as long as $3 \mathrm{~d}$ after the disbudding procedure

Veterinarians take administration of pain medication to the calf seriously

It is too expensive to have a veterinarian medicate the calf for disbudding

Sedation causes more problems for the calf than disbudding without medication

Painless disbudding increases the calf's welfare

I could never disbud calves without administering pain medication

Dehorned dairy cattle cause fewer injuries to others than horned cattle

Horns pose no risk to the stockperson

Sawing off the animals horns is a better alternative than disbudding

Calves should never be disbudded

Fully-orown cows need their horns

If I could inject the calf with pain medication myself before disbudding, I would

If I could inject the calf with anesthetics myself before the disbudding procedure

(inject an anesthetic substance around the horn buds), I would

If I could tranquilize (anaesthetize) the calf myself, I would

$\begin{array}{lr}5(1) & 0.79 \\ 1(2) & -0.69 \\ 3(2) & 0.37 \\ 4(2) & 0.52 \\ 4(3) & -0.60 \\ 2(2) & -0.69 \\ 5(1) & 0.55 \\ 3(4) & 0.70\end{array}$

tatement about cattle pain (VAS)

Disbudding without pain medication (pain during the burning)

Navel infection in a calf (navel is thick and moist, animal is feverish)

Acute mastitis

Uterine prolapse in cattle

Umbilical hernias the size of a large apple in a calf

Abomasal displacement in cattle

Severe tympania in cattle

Teat tramping in cows (teat broken at the root)

Eigenvalues of the factors

$5(0)$

1 (1)

$1(1)$

$1(1)$

Variance explained \% (total 36.9\%)

0.68

() Attitudes to disbudding: $1=$ completely disagree, $5=$ completely agree. Pain in dairy cattle: $0=$ no pain, 10 most severe pain. $\mathrm{n}=435$ 


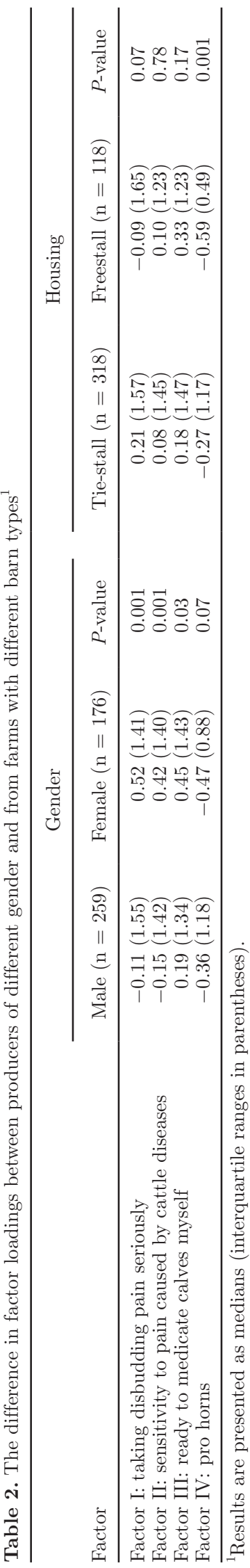

seriously") and a lower median negative loading for factor IV ("pro horns"; Mann-Whitney, $P<0.05$ ). Female producers with freestalls had a higher positive median loading for factor III ("ready to medicate calves myself") and females with tie-stalls had a lower negative median loading for factor IV ("taking disbudding pain seriously"; Mann-Whitney, $P<0.05$ ).

\section{Correlations Between Factor Loadings}

A positive significant correlation existed for factor I ("taking disbudding seriously") and factor II ["sensitivity to pain caused by cattle diseases"; Spearman correlation $\left(\mathrm{r}_{\mathrm{s}}\right)=0.31, P=0.001$, but no other significant correlations between factor loadings were established.

\section{Relationship Between Factor Loadings and Mean Milk Yield}

Producers on farms in different milk yield categories differed in their loadings for factor III ("ready to medicate calves myself") and factor IV ("pro horns"; Table 4; Kruskal-Wallis, $P=0.001$ for both), whereas no associations were established for the other factors. The farms with an annual milk yield maximum of 8,000 L had the lowest loadings for factor III ("ready to medicate calves myself") and factor IV ("pro horns") compared with the higher-milk-yielding farms (MannWhitney, $P<0.05$ for all).

\section{Relationships Between the Factor Loadings and Mean Herd Size}

The factor loadings did not differ significantly among farms of different mean herd size for factor I ("taking disbudding pain seriously"), factor II ("sensitivity to pain caused by cattle diseases"), or factor III ("ready to medicate calves myself"; Kruskal-Wallis, $P>0.05$ ). Loadings for factor IV ("pro horns"), however, did differ among the different sized farms (Kruskal-Wallis, $P$ $=0.001$ ), in which the smallest herd size differed from the other herd sizes (Mann-Whitney, $P=0.003$, for all). Results are presented as medians and interquartile ranges for factor IV ("pro horns"): $\mathrm{n}=197,1-20$ cows $(0.07,1.47) ; \mathrm{n}=162,21-40$ cows $(-0.53,0.74) ; \mathrm{n}=$ $48,41-60$ cows $(-0.57,0.47)$; and $\mathrm{n}=21$, over 61 cows $(-0.65,0.33)$.

\section{The Relationship Between Factor Loadings and Age and Work Experience of Respondent}

The factor loadings did not differ significantly among respondents of different age for factor I ("taking disbudding pain seriously") or factor III ("ready to medicate 
Table 3. The difference in factor loadings between female and male producers with tie-stalls and freestalls ${ }^{1}$

\begin{tabular}{|c|c|c|c|c|c|c|}
\hline \multirow[b]{2}{*}{ Factor } & \multicolumn{3}{|c|}{ Male } & \multicolumn{3}{|c|}{ Female } \\
\hline & Tie-stall $(\mathrm{n}=196)$ & Freestall $(\mathrm{n}=60)$ & $P$-value & Tie-stall $(\mathrm{n}=119)$ & Freestall $(\mathrm{n}=57)$ & $P$-value \\
\hline Factor I: taking disbudding pain seriously & $0.09(1.36)$ & $-0.59(1.69)$ & 0.01 & $0.62(1.51)$ & $0.19(1.12)$ & 0.29 \\
\hline Factor II: sensitivity to pain caused by cattle diseases & $-0.07(1.40)$ & $-0.31(1.59)$ & 0.07 & $0.45(1.52)$ & $0.40(1.23)$ & 0.73 \\
\hline Factor III: ready to medicate calves myself & $0.20(1.32)$ & $0.09(1.47)$ & 0.32 & $0.20(1.73)$ & $0.78(1.04)$ & 0.01 \\
\hline Factor IV: pro horns & $-0.10(1.32)$ & $-0.63(0.43)$ & 0.001 & $-0.43(0.92)$ & $-0.58(0.68)$ & 0.02 \\
\hline
\end{tabular}

${ }^{1}$ Results are presented as medians (interquartile ranges in parentheses).

Table 4. The difference in factor loadings among producers from farms with different milk yields $(\mathrm{n}=432)^{1}$

Yearly mean milk yield

\begin{tabular}{|c|c|c|c|c|}
\hline \multirow[b]{2}{*}{ Factor } & & \multirow[b]{2}{*}{$P$-value } \\
\hline & $\leq 8,000 \mathrm{~L} / \mathrm{yr}(\mathrm{n}=119)$ & $8,001-10,000 \mathrm{~L} / \mathrm{yr}(\mathrm{n}=243)$ & $\geq 10,000 \mathrm{~L} / \mathrm{yr}(\mathrm{n}=70)$ & \\
\hline Factor I: taking disbudding pain seriously & $0.07^{\mathrm{a}}(1.59)$ & $0.02^{\mathrm{a}}(1.64)$ & $0.39^{\mathrm{a}}(1.20)$ & 0.12 \\
\hline Factor II: sensitivity to pain caused by cattle diseases & $0.08^{\mathrm{a}}(1.52)$ & $0.14^{\mathrm{a}}(1.40)$ & $0.13^{\mathrm{a}}(1.37)$ & 0.97 \\
\hline Factor III: ready to medicate calves myself & $-0.09^{\mathrm{a}}(1.54)$ & $0.33^{\mathrm{b}}(1.25)$ & $0.45^{\mathrm{b}}(1.29)$ & 0.001 \\
\hline Factor IV: pro horns & $0.13^{\mathrm{a}}(1.60)$ & $-0.46^{\mathrm{b}}(0.91)$ & $-0.58^{\mathrm{b}}(0.84)$ & 0.001 \\
\hline
\end{tabular}

$\overline{\mathrm{a}, \mathrm{b}}$ Values lacking common superscript letters are significantly different $(P<0.05)$ in pairwise comparisons.

$-0.58^{\mathrm{b}}(0.84$

0.001

${ }^{1}$ Results are presented as medians (interquartile ranges in parentheses). 
calves myself"; Kruskal-Wallis, $P>0.05)$. On the other hand, a difference existed for factor III among the age categories, in which producers over 55 yr of age differed from producers aged 39 and younger (Mann-Whitney, $P=0.028$ ). Loadings for factor II ("sensitivity to pain caused by cattle diseases"), however, did differ among the producers of different ages (Kruskal-Wallis, $P=$ 0.021 ), in which producers over 55 yr of age differed from producers aged 40 to $56 \mathrm{yr}$ (Mann-Whitney, $P$ $=0.018)$ and from producers aged $39 \mathrm{yr}$ and younger (Mann-Whitney, $P=0.05$ ). Also loadings for factor IV ("pro horns") did differ among the producers of different ages (Kruskal-Wallis, $P=0.041$ ), in which producers over $55 \mathrm{yr}$ of age differed from producers aged $39 \mathrm{yr}$ and younger (Mann-Whitney, $P=0.034$ ). Results are presented as medians and interquartile ranges: for factor II ("sensitivity to pain caused by cattle diseases"): $\mathrm{n}=109,55 \mathrm{yr}$ and older $(0.34,1.35) ; \mathrm{n}=241,40$ to 54 $\mathrm{yr}(-0.03,1.38)$; and $\mathrm{n}=83,39 \mathrm{yr}$ and younger $(0.08$, $1.45)$; for factor III ("ready to medicate calves myself"): $\mathrm{n}=109,55 \mathrm{yr}$ and older $(0.20,1.70) ; \mathrm{n}=241,40$ to 54 yr $(0.23,1.39)$; and $\mathrm{n}=83,39$ years and younger $(0.46$, 0.91 ); for factor IV ("pro horns"): $\mathrm{n}=109,55 \mathrm{yr}$ and older $(-0.27,1.36) ; \mathrm{n}=241,40$ to 54 yr $(-0.39,1.14)$; and $\mathrm{n}=83,39 \mathrm{yr}$ and younger $(-0.51,0.51)$.

The median loadings for factor IV ("pro horns") differed among producers within different work experience categories (Kruskal-Wallis, $P=0.013$ ), but factors I to III did not differ. Pairwise comparison tests with a Bonferroni correction did not differ significantly in the different work experience categories.

\section{DISCUSSION}

We present 4 factors that describe dairy producer attitudes toward cattle pain and the necessity for cattle having horns. The respondents' gender and their barn type were related to their attitudes.

\section{The Factors}

We termed the factor that described producers' acknowledgment of calf pain and agreeing that disbudding without medication is painful for the calf as factor I ("taking disbudding pain seriously"). Those producers (Table 1) that took disbudding pain seriously were keen to alleviate pain in the disbudded calves and, accordingly, did not agree that disbudding pain should be left untreated. It has been suggested that the cost of the analgesic used during disbudding usually represents a disincentive for the producer (Huxley and Whay, 2006) and producers may not be willing to pay the extra cost (Hudson et al., 2008; Gottardo et al., 2011). However, in previous studies (Hewson et al., 2007; Hokkanen et al., 2011), producers who estimated the disbuddingrelated pain to be higher and suggested that it should be treated also valued veterinary services more and were ready to pay for them.

Interestingly, factor I ("taking disbudding seriously") correlated with factor II ("sensitivity to pain caused by cattle diseases"), which means that respondents sensitive to cattle pain also took into account pain related to disbudding. This is somewhat similar to previous findings in which producers with positive attitudes to animal welfare scored higher for empathy for perception of animal pain questions than the producers with negative attitudes (Kielland et al., 2010).

According to our results, respondents would like to medicate their calves themselves before disbudding (factor III). In Nordic countries, the drugs administered to animals are controlled strictly by legislation (Act on Medical Treatment of Animals 617/1997; Finlex, 1997), so it is not possible for the producer to use local anesthetics or sedatives to alleviate disbudding-related pain.

The respondents who preferred cows with horns had positive loadings for the statements on keeping the horns and were hence termed factor IV ("pro horn"). Such producers did not think that dehorned cattle were safer than horned cattle, or that horns represented a risk to the stockperson. Pro-horn producers were also not keen on disbudding calves and stated that cattle needed their horns. These results are comparable with those found in a recent study by Gottardo et al. (2011) in which producers kept cattle with horns mainly for aesthetic reasons, lack of time (to disbud), and tradition. Also, in that study, $74 \%$ of the respondents reported that handling horned cattle was not difficult.

\section{Barn Type and Gender}

A relationship existed between the number of dairy cows on a farm and a respondent's attitudes. This result needs to be generalized with caution; however, as the overall farm size in Finland is considerably smaller compared with some other countries. We suggest that this effect of farm size may be due to an underlying cultural difference associated with farms of different size, and not only with the actual number of animals on farm.

Interestingly, barn type was not associated with respondent attitudes toward treating disbudding pain: male producers with a tie-stall system had particularly higher loadings for factor I ("taking disbudding seriously") than those with freestalls. We previously showed that even though disbudding in a freestall system is frequent, pain alleviation is valued more in smaller tiestall barns (Hokkanen et al., 2011). This might reflect 
the less-frequent human-animal interactions on larger farms. The finding is somewhat similar to that for a previous study on pig farms in which the producers on bigger farms perceived treating animals humanely as being more difficult than on smaller farms (Kauppinen et al., 2012). This finding is also supported by Dockès and Kling-Eveillard (2006), in that on smaller dairy cattle farms, producers pay more attention to individual animals, compared with larger cattle farms where they pay more attention to the producer's working conditions and income than to the welfare of individual cows.

Producers with tie-stalls were more positive about keeping the cows with horns in a herd than producers with freestalls barns. This is most likely due to barn size, tradition, and safety issues, as horns represent less risk for the stockperson and other animals in tie-stalls because the cow's movements are restricted. Almost $40 \%$ of producers did not disbud animals in tie-stalls and less than $1 \%$ did so for animals in freestalls. Disbudding is often justified by the assumption that hornless cattle are safer to handle than horned cattle.

Female producers had higher loadings for factor I ("taking disbudding pain seriously") and factor II ("sensitivity to pain caused by cattle diseases"). This is similar to findings of several other studies where females rated cattle pain higher than males (Huxley and Whay, 2006; Kielland et al., 2009; Laven et al., 2009). Female producers were also more likely than male producers to want to treat calf pain themselves. Also female veterinarians assess pain higher and use more pain medication than male veterinarians (Capner et al., 1999; Raekallio et al., 2003; Huxley and Whay, 2006).

\section{Age and Work Experience of the Producer and Herd Size}

Older producers (over 55 yr old) had higher loadings for factor II ("sensitivity to cattle pain caused by cattle diseases") than middle-aged and young producers. The knowledge of different cattle diseases and the complexity of treating the animals may be one factor making older producers more sensitive to cattle pain (Huxley and Whay, 2006). This corresponds with the findings of Kielland et al. (2010), who showed that personal experience with various cattle sicknesses was connected with higher empathy scores. Similarly, more experienced veterinary nurses assign higher pain scores to animals (Coleman and Slingsby, 2007). On the other hand, younger producers (under $39 \mathrm{yr}$ ) had higher loadings for factor III ("ready to medicate calves myself") than older producers, as reported for younger veterinarians who give more pain medication than older colleagues (Raekallio et al., 2003). However, we did not establish that producer age had an effect on factor I ("taking disbudding pain seriously"), which differed for older cattle veterinarians who rated dehorning pain higher than younger colleagues (Huxley and Whay, 2006).

Factor IV ("pro horn") was associated with a producer's work experience and the herd size. Also, older producers (over $55 \mathrm{yr}$ old) had lower negative loadings for the pro-horn factor than younger producers. We suggest that more experienced and older producers with smaller herds may be keen to keep calves horned, as it is the traditional way of managing cows in small herds. Less-experienced and younger producers with larger herds consider disbudding to be a modern, and safer, way of managing dairy cows.

In small farms, the use of veterinary services represents an extra cost for the producer; hence, disbudding and pain medication cost and the option to keep cattle with horns is less expensive. In Finland, the veterinarian charges producers by number of visits and according to the services required. In larger freestall systems, disbudding and administration of pain medication are done routinely by the veterinarian, so producers with larger herds are more willing to medicate calves themselves and are less positive about keeping cattle with horns.

\section{Milk Yield}

The producers with low-milk-yielding herds were less willing to self-medicate their calves and more willing to keep cattle with horns. However, milk yield was not correlated with the factors describing a respondent's attitude to taking disbudding pain seriously and being sensitive to cattle pain. This partly contradicts a previous finding in which high milk yields were reported to be associated with positive attitudes toward humananimal interactions (Waiblinger et al., 2002; Hanna et al., 2009). But, on the other hand, dairy producers with the highest pain score have also shown to have a high level empathy, a positive attitude to animals, and low milk production (Kielland et al., 2010). But in this study, no association was found between milk yield and pain perception.

\section{CONCLUSIONS}

We found 4 main factors related to attitudes to animal pain, sensitivity to pain caused by cattle diseases, ready to medicate calves oneself, and the importance of maintaining horned cattle. Taking disbudding seriously correlated with sensitivity to pain caused by cattle diseases. We found that female producers rated pain higher and were more positive toward pain medication for animals and also more willing to medicate calves themselves than male producers. Male dairy producers 
with a tie-stall system took disbudding pain more seriously than those with a freestall system. Dairy producers wanted to medicate calves themselves in a freestall system more than in a tie-stall system. A producer's attitude to maintaining horns was more positive in a tie-stall system than in a freestall system.

\section{ACKNOWLEDGMENTS}

This study was funded by the Ministry of Agriculture and Forestry in Finland (Helsinki) and with grants awarded by the Finnish Veterinary Foundation (Helsinki, Finland), the Swedish Cultural Fund (Helsinki, Finland), and the Swedish Ostrobothnian Society (Vaasa, Finland). We thank our sponsors Valio Ltd. (Helsinki, Finland), Vetman Ltd. (Halikko, Finland), Viking Genetics (Hollola, Finland), and Osuuskunta Maitosuomi (Seinäjoki, Finland). We thank all the farmers that took part in the study.

\section{REFERENCES}

Ajzen, I. 2002. Perceived behavioral control, self-efficacy, locus of controls and the theory of planned behavior. J. Appl. Soc. Psychol. 32:665-683.

ALCASDE (Alternatives to Castration and Dehorning). 2009. Final report: Study on the improved methods for animal-friendly production, in particular on alternatives to the castration of pigs and on alternatives to the dehorning of cattle. SANCO/2008/D5/018. Accessed Aug. 24, 2012. http://ec.europa.eu/food/animal/welfare/farm/ alcasde_study_04122009_en.pdf.

AVA (Australian Veterinary Association). 2004. Policy Compendium on Cattle Health and Welfare. Accessed Apr. 22, 2013. http:// www.ava.com.au/policy/84-dehorning-cattle.

AVMA (American Veterinary Medical Association). 2012. Welfare implications of dehorning and disbudding of cattle. Accessed Apr. 22, 2013. https://www.avma.org/KB/Policies/Pages/Castrationand-Dehorning-of-Cattle.aspx.

Broom, D. M. 1991. Assessing welfare and suffering. Behav. Process. $25: 117-123$

Capner, C. A., B. D. Lascelles, and A. E. Waterman-Pearson. 1999. Current British veterinary attitudes to perioperative analgesia for dogs. Vet. Rec. 145:95-99.

Coleman, D. L., and L. S. Slingsby. 2007. Attitudes of veterinary nurses to assessment of pain and the use of pain scales. Vet. Rec. 160:541-544

Coleman, G. J., M. McGregor, P. H. Hemsworth, J. Boyce, and S. Dowling. 2003. The relationship between beliefs, attitudes and observed behaviours of abattoir personnel in the pig industry. Appl. Anim. Behav. Sci. 82:189-200.

Dockès, A. C., and F. Kling-Eveillard. 2006. Farmers' and advisers' representations of animals and animal welfare. Livest. Sci. 103:243-249

Fajt, V. R., S. A. Wagner, and B. Norby. 2011. Analgesic drug administration and attitudes about analgesia in cattle among bovine practitioners in the United States. J. Am. Vet. Med. Assoc. 238:755-767.

Finlex. 1997. Act on the Medical Treatment of Animals 617/1997 by the Council of State on 27th of June 1997, Finland. Accessed Apr. 22, 2013. http://www.finlex.fi/fi/laki/ajantasa/1997/1997061. [Legislation in Finnish].

Fulwider, W. K., T. Grandin, B. E. Rollin, T. E. Engle, N. L. Dalsted, and W. D. Lamm. 2008. Survey of dairy management practices on one hundred thirteen North Central and Northeastern United States dairies. J. Dairy Sci. 91:1686-1692.

Gottardo, F., E. Nalon, B. Contiero, S. Normando, P. Dalvit, and G. Cozzi. 2011. The dehorning of dairy calves: Practices and opinions of 639 farmers. J. Dairy Sci. 94:5724-5734.

Grandin, T. 2000. Introduction: Management and economic factors of handling and transport. Pages 1-14 in Livestock Handling and Transport. 2nd ed. T. Grandin, ed. CABI Publishing, Wallingford, UK.

Hanna, D., I. A. Sneddon, and V. E. Beattie. 2009. The relationship between the stockperson's personality and attitudes and the productivity of dairy cows. Animal 3:737-743.

Hazel, S. J., T. D. Signal, and N. Taylor. 2011. Can teaching veterinary and animal-science students about animal welfare affect their attitude towards animals and human-animal related empathy. J. Vet. Med. Educ. 38:74-83.

Hemsworth, P. H. 2003. Human-animal interactions in livestock production. Appl. Anim. Behav. Sci. 81:185-198.

Hemsworth, P. H., G. J. Coleman, J. L. Barnett, S. Borg, and S Dowling. 2002. The effects of cognitive behavioral intervention on the attitude and behavior of stockpersons and the behavior and productivity of commercial dairy cows. J. Anim. Sci. 80:68-78.

Hewson, C. J., I. R. Dohoo, K. A. Lemke, and H. W. Barkema. 2007. Factors affecting Canadian veterinarians' use of analgesics when dehorning beef and dairy calves. Can. Vet. J. 48:1129-1136.

Hojat, M., S. Mangione, T. J. Nasca, S. Rattner, J. B. Erdman, J. S. Gonnella, and M. Magee. 2004. An empirical study of decline in empathy in medical school. Med. Educ. 38:934-941.

Hokkanen, A. H., T. Korhonen, M. Pastell, A. Valros, O. Vainio, and L. Hänninen. 2011. Perception and practices of Finnish dairy producers regarding disbudding of calves. Page 14 in Proc. 23rd Nordic Symp. ISAE, Tartu, Estonia. Ecoprint, Tartumaa, Estonia.

Hudson, C., H. Whay, and J. Huxley. 2008. Recognition and management of pain in cattle. In Practice 30:126-134

Huxley, J. N., and H. R. Whay. 2006. Current attitudes of cattle practitioners to pain and the use of analgesics in cattle. Vet. Rec. 159:662-668.

Kauppinen, T., K. M. Vesala, and A. Valros. 2012. Farmer attitude toward improvement of animal welfare is correlated with piglet production parameters. Livest. Sci. 143:142-150.

Kielland, C., E. Skjerve, O. Østerås, and A. J. Zanella. 2010. Dairy farmer attitudes and empathy toward animals are associated with animal welfare indicators. J. Dairy Sci. 93:2998-3006.

Kielland, C., E. Skjerve, and A. J. Zanella. 2009. Attitudes of veterinary students to pain in cattle. Vet. Rec. 165:254-258.

Knapp, T., and J. K. Brown. 1995. Ten measurements commandments that often should be broken. Res. Nurs. Health 18:465-469.

Laven, R. A., J. N. Huxley, H. R. Whay, and K. J. Stafford. 2009. Results of a survey of attitudes of dairy veterinarians in New Zealand regarding painful procedures and conditions in cattle. N. Z. Vet. J. $57: 215-220$.

Misch, L. J., T. F. Duffield, S. T. Millman, and K. D. Lissemore 2007. An investigation into the practices of dairy producers and veterinarians in dehorning dairy calves in Ontario. Can. Vet. J. 48:1249-1254.

Neumann, M., F. Edelhäuser, D. Tauschel, M. R. Fischer, M. Wirtz, C. Woopen, A. Haramati, and C. Scheffer. 2011. Empathy decline and its reasons: A systematic review of studies with medical students and residents. Acad. Med. 86:996-1009.

New Zealand Government. 2005. AnimalWelfare(PainfulHusbandry Procedures) Code of Welfare 2005. Accessed Apr. 22, 2013. http://www. biosecurity.govt.nz/files/regs/animal-welfare/req/codes/painfulhusbandry/painful-husbandry.pdf.

Niemi-Murola, L., J. T. Nieminen, E. Kalso, and R. Pöyhiä. 2007. Medical undergraduate students' beliefs and attitudes toward pain: How do they mature? Eur. J. Pain 11:700-706.

Paul, E. S., and A. L. Podberscek. 2000. Veterinary education and students' attitudes towards animal welfare. Vet. Rec. 146:269-272.

Raekallio, M., K. M. Heinonen, J. Kuussaari, and O. Vainio. 2003. Pain alleviation in animals: Attitudes and practices of Finnish veterinarians. Vet. J. 165:131-135. 
Raussi, S. 2003. Human-cattle interactions in group housing. Appl. Anim. Behav. Sci. 80:245-262.

Tike (Information Centre of the Ministry of Agriculture and Forestry). 2011. Matalouslaskenta 2010. Kotieläinten elinolot ja lannan varastointi. Accessed Aug. 24, 2012. http://www.maataloustilastot. fi/e-lehti-kotielaimet/. (In Finnish.)

Vaartio, H., H. Leino-Kilpi, T. Suominen, and P. Puukka. 2009. Measuring nursing advocacy in procedural pain care-Development and validation of an instrument. Pain Manag. Nurs. 10:206-219.

Viñuela-Fernández, I., E. Jones, E. M. Welsh, and S. M. FleetwoodWalker. 2007. Pain mechanisms and their implication for the management of pain in farm and companion animals. Vet. J. $174: 227-239$.

Waiblinger, S., C. Menke, and G. Coleman. 2002. The relationship between attitudes, personal characteristics and behaviour of stock people and subsequent behaviour and production of dairy cows. Appl. Anim. Behav. Sci. 79:195-219.

Weary, D. M., L. Niel, F. C. Flower, and D. Fraser. 2006. Identifying and preventing pain in animals. Appl. Anim. Behav. Sci. 100:64-76.

Zhan, L., and C. Shen. 1994. The development of an instrument to measure self-consistency. J. Adv. Nurs. 20:509-516. 